\section{Chemical carcinogens}

Chemical Carcinogens. (ACS Monograph 173.) By C. E. Searle. Pp. xxvii +788. (American Chemical Society: Washington, DC, 1976.) \$67.50.

THAT most cancer in man is caused by chemicals is now accepted, although the first demonstration of cancer produced by a pure chemical compound was only published in 1930 as a postscript to a paper by E. L. Kennaway. Before that there was evidence that soot, coal tar, pitch, and some oils caused cancer in man; and soon after Kennaway's successful experiment the widely distributed carcinogen, benzopyrene, was isolated from coal tar and synthesised. These experiments opened the gates to a flood of research in chemical carcinogenesis. Most cancer in man is caused by chemical substances in the environment and a sure way of preventing cancer is to identify these carcinogens and remove them. Such removal is not always feasible in practice. The most ubiquitous cause of cancer in Britain is tobacco but it seems impossible to prevent smoking. The active chemical carcinogen or carcinogens in tobacco smoke are still not known and attempts to make 'safer' cigarettes are hampered by the lack of knowledge.

The existing knowledge of chemical carcinogens and the research in the problems are so vast that it is difficult for individuals or even teams of workers to cover the subject. The volume under review is an admirable and much needed attempt to present the available facts and some of the theories. The main gap in the book is that inorganic carcinogens, except asbestos, are not considered.

The editor points out that this is not the first effort to list a catalogue of chemical carcinogens. The US Department of Health, Education and Welfare has published a series entitled Survey of Compounds Which Have Been Tested for Carcinogenic Activity, some of which were edited by Hartwell and Shubik. The first of the series appeared in 1951 and the last, which is generally available, includes data published in 1971. The International Agency for Research on Cancer in Lyon has published twelve monographs on the Evaluation of the Carcinogenic Risk to Man. These monographs are invaluable to research workers and administrators concerned with cancer problems. In very few cases, however, is it possible to evaluate the potential carcinogenic hazard to man of pure chemical compounds.

In addition to the preface written by the editor, which is an excellent review of the present position of the subject, there are 16 chapters written by 23 experts in their fields. There is less repetition than would be expected with a book written by so many authors. The chapters on "Soots, tars and oils" by Kipling, on "Laboratory hazards" by George and Searle and on "The Bracken Carcinogen" by I. A. Evans and "Asbestos" by Wagner, are each about 10 pages. The chapter on "N-Nitroso Compounds" by Magee, Montesano and Preussmann is an authoritative review of the subject covering 125 pages. In the case of this and other articles it would be of value and interest to know when they were written.

There are also comprehensive reviews

\section{Perception handbook}

Handbook of Perception. Vol 7: Language and Speech. Edited by E. C. Carterette and M. P. Friedman. Pp. xviii +501 . (Academic: New York and London, 1976.) £16.25.

A successful handbook has the opposite fate to a 'classic': it is consulted, but not quoted. It is used to settle disputes, to aid memory, and to fill in inevitable gaps in knowledge. To these ends it must be well organised, comprehensive, and authoritative. In psychology, the standard was set by S. S. Stevens's Handbook of Experimental Psychology which was first published in 1951. Carterette and Friedman are engaged in the publication of a more ambitious work, a ten-volume handbook intended "for all in the arts or sciences.. . who are interested in human perception". The first six volumes are concerned with fundamentals, and the present volume is the first to be devoted to a wider consideration of the contents of perception rather than particular processes or modalities.

There are fourteen chapters arranged in four parts: fundamental aspects of language and speech; coding, perception, and hearing; disorders of language and speech; and trends in psychological tests of linguistic theory. These headings are not auspicious and certainly do not reflect a natural organisation of the field. The assignment of topics to them turns out to be fairly arbitrary, and the problem of finding one's way through the book is further aggravated by a considerable degree of overlap between the contents of the chapters. Accounts of the production of speech crop up in three different places, varying considerably in detail, and there are numerous cases of brief descriptions of the same work occurring in more than one chapterfor example, the subjective location of clicks, Katz's theory of semantics, and on endocrine aspects, alkylating agents, polynuclear aromatic carcinogens, environmental respiratory carcinogenesis, aromatic amines, carcinogens in plants and microorganisms, and metabolism of chemical carcinogens.

The book is well produced, easy to handle considering its size, and provides an excellent overview and reference work, although it is already out of date in some minor matters.

E. Boyland

E. Boyland is Visiting Professor in Environmental Toxicology at the School of Hygiene and Tropical Medicine, London, $U K$.

Winograd's program for understanding natural language.

The book ranges reasonably comprehensively over the major topics in the area, and includes useful chapters on speech perception (C. Darwin), the syntactic analysis of sentences (J. M. Carroll and T. G. Bever), the research methods of psycholinguistics (G. Olson and $\mathrm{H}$. Clark), non-verbal communication (J. Laver), and aphasia (H. Goodglass and N. Geschwind). Somewhat surprisingly, it also has chapters on language teaching and language learning, disorders in speech production, and the general development of language in children. Yet, a number of topics very relevant to perception do not have chapters devoted to themfor example, intonation and tone of voice, the psychology of reading, and computer programs for understanding speech. At a more technical level, the reader will look in vain for an account of linear prediction theory, augmented transition networks, the perception of illocutionary force, and procedural semantics. It is probably no coincidence that each of these topics reflects an increasing concern with psychological processes in real time rather than with the static structures of linguistic theory. Ironically, the chapter that best captures this growing preoccupation, MacNeilage and Ladefoged's excellent discussion of speech production, is concerned with perception in only a tangential way.

In summary, the compilers have solicited a number of authoritative articles from acknowledged experts, but they have failed to cover the field comprehensively and to edit the materials to the best advantage. They have produced a superior symposium rather than an indispensable handbook.

\section{P. N. Johnson-Laird}

P. N. Johnson-Laird is Reader in Experimental Psychology at the University of Sussex, UK. 